\title{
High-Performance Work System and Employee Counterproductive Work Behavior: The Perspective of Employee Perception
}

\author{
Ling Peng, ${ }^{1}$ Jiafu Su $\mathbb{D}^{2,3}$ Yupei Du ${ }^{2},{ }^{4}$ and Muzi $\mathrm{Li}^{5}$ \\ ${ }^{1}$ Guangdong University of Science and Technology, Dongguan, China \\ ${ }^{2}$ International College, Krirk University, Bangkok, Thailand \\ ${ }^{3}$ National Research Base of Intelligent Manufacturing Service, Chongqing Technology and Business University, Chongqing, China \\ ${ }^{4}$ International College, National Institute of Development Administration, Bangkok, Thailand \\ ${ }^{5}$ School of International Law, Southwest University of Political Science and Law, Chongqing, China \\ Correspondence should be addressed to Yupei Du; fion1031@163.com
}

Received 28 July 2021; Revised 20 October 2021; Accepted 30 October 2021; Published 19 November 2021

Academic Editor: Yi Su

Copyright (c) 2021 Ling Peng et al. This is an open access article distributed under the Creative Commons Attribution License, which permits unrestricted use, distribution, and reproduction in any medium, provided the original work is properly cited.

\begin{abstract}
Employee counterproductive work behavior (ECWB) in the workplace has caused serious harm to the organization, and its recessive occurrence creates difficulty for the organization to guard against it. This study aims to explore the influence of highperformance work systems (HPWS) on the two sides of ECWB with employees and the internal influence path. It also aims to combine resource conservation and affective events theories to build an HPWS five-level model. It provides human resource management measures for enterprises to reduce and prevent the ECWB effectively. This study adopts a quantitative analysis method to conduct a questionnaire survey among employees in 366 enterprises in China. The results show that HPWS has a significant two-sided impact on ECWB. For employees with positive emotions, HPWS improved employee performance and inhibited ECWB. Meanwhile, for employees with negative emotions, HPWS reduces employees' work input and increases employees' counterproductive behaviors. For negative employees, the positive effect of HPWS is more significant than the negative effect of positive employees. In addition, organizational commitment has a moderating effect on the counterproductive behavior of negative employees. Therefore, when implementing HPWS, enterprises should consider the impact of both sides of HPWS on ECWB and adopt a more humane management method. In this study, a practical five-level HPWS model is constructed, which complements the existing research model and provides a theoretical basis and practical guidance for enterprises to scientifically and effectively promote employees to achieve high performance.
\end{abstract}

\section{Introduction}

With the increasingly fierce market competition, enterprises are facing great challenges. How to maintain a good employment relationship is an eternal problem that enterprises must face. As an implicit and ubiquitous problem, counterproductive behavior refers to the explicit or implicit harmful behavior of employees in the workplace toward the organization and its stakeholders [1]. Zhang and Wang [2] found 13 kinds of counterproductive behavior, such as rude behavior, violent behavior, theft, and destruction, in organizations to varying degrees. With the development of science and technology and the dawn of the big data era, counterproductive behaviors of employees have become more insidious and destructive (e.g., data leakage and selling of user information), causing irreversible losses to enterprises and society, thereby posing the most challenging problem for modern enterprises. Reducing ECWB has become critical in enterprise human resource management (HRM) practice.

With the development of management practices and the advancement of research, some researchers found that highperformance work systems (HPWS) are the best HRM practice system. It can reduce ECWB to a certain extent [3]. 
However, some studies have pointed out that the HPWS may increase the turnover rate of employees [4]. Van et al. [5] believed that employees' perception and understanding of the purpose of HPWS implemented by managers determine employees' attitudes and behaviors. The accumulation of resources determines an individual's perception of work, thus affecting his or her willingness to invest or retain resources in work. For example, employees with abundant resources perceive the HPWS implementation as motivation and may have positive emotions. Meanwhile, employees who lack their own resources perceive HPWS as performance and great work pressure, which may lead to negative emotions [6]. Therefore, employee emotion is considered as the mediating mechanism of the work event-work outcome relationship [7]. In addition, in implementing HPWS, employees perceive high work requirements, thus producing more stress and frequent ECWB. Therefore, how to relieve employees' work pressure has become an urgent problem for contemporary enterprises. According to Hunter and Thatcher [8], organizational commitment can weaken employee's negative behavior and strengthen their positive behavior. It can effectively transform work pressure into work motivation and produce higher job performance. Therefore, based on the perspective of employee perception, this study constructs structural equation modeling to explore the influence path of the duality of HPWS on ECWB. Simultaneously, the theories of resource preservation and employee work emotion are combined. Employee emotion and organizational commitment were introduced into the model as mediating and moderating variables, respectively. Furthermore, this study explores the mechanism of action between HPWS and ECWB. Finally, an HPWS five-level model is constructed. It provides a scientific solution for enterprises to effectively implement different HRM methods for individuals. This study expands the theoretical basis of HPWS on ECWB. It provides theoretical basis and practical guidance for modern enterprises to construct harmonious labor-capital relationship and HRM practice.

\section{Related Concepts and Research Hypotheses}

\subsection{Research Hypothesis}

2.1.1. HPWS Perception and ECWB. HPWS is a collection of various HRM practice activities, which is the sum of a series of activities and policies used to ensure that HRM serves the strategic objectives of the enterprise [9]. The perceived HPWS refers to whether HPWS is accurately and clearly perceived and understood by employees. Its components mainly include employment safety, recruitment, training, promotion, salary, incentive, and employee participation [10]. Meanwhile, ECWB refers to the intentional harm to the organization and its stakeholders conducted by organization members in the workplace [11].

According to the theory of resource conservation, when employees are in a state of sufficient resources, they are more inclined to invest the "redundant" resources to obtain more. When employees are in a state of resource deficiency, they are more inclined to take ECWB to reduce the further loss of "surplus" resources. Therefore, when employees are in a state of sufficient resources, they perceive that the purpose of implementing HPWS is to motivate them, and they will be more willing to invest resources to gain more value. In contrast, when employees are in a state of resource shortage, they perceive that implementing HPWS aims to maximize performance; thus, they will reduce work input to reduce the consumption of resources. Hu et al. [6] also supported this theory. When employees make performance attribution of HPWS, they will think that HPWS is a management system with the core of controlling or making full use of employees, which will increase ECWB. Moreover, when employees make HPWS well-being attribution, they will believe that HPWS is for realizing their value, which will reduce the ECWB. Shaw [12] conducted a questionnaire survey on 302 service companies in the United States. The findings revealed that high participation in work organization practice, investment, and incentive practices led to low turnover and dismissal rates. Moreover, the performance enhancement practice dimension leads to a high turnover rate and high dismissal rate. Meanwhile, Batt and Colvin [4] also confirmed the duality of HPWS; they found that incentives and investment practices were negatively correlated with turnover rate. The role of expected enhancement practices varies from person to person (high and low achievers) [4]. To sum up, employees' HPWS perception is divided into investment and incentive practice perception (IIPP) and performance enhancement practice perception (PEPP) in this study, and the following hypotheses are proposed:

$\mathrm{H} 1$ : investment and incentive practice perception have a significant negative influence on ECWB

$\mathrm{H} 2$ : the performance enhancement practice perception has a significant positive influence on ECWB

2.1.2. HPWS Perception and Employee Emotion. Emotion is a kind of psychological activity mediated by the individual's desire and need. When objective, things, or situations meet the needs and desires of the subject, positive moods and emotions can be aroused. In contrast, negative moods and emotions will be generated, which is the maintenance or change of a certain relationship between the individual and the environment [13]. Warr [14] put forward the negative and positive emotions related to work. Negative emotions include depression, pain, worry, and tension. Meanwhile, positive emotions include being relaxed, satisfied, calm, optimistic, and enthusiastic. These emotions were significantly correlated with the employee's experience at work.

As the core goal of HPWS is to improve enterprise performance, it brings not only high resources to employees but also high work requirements $[15,16]$. This duality generates different views from different employees, thus arousing corresponding emotions. Very high-performanceoriented work requirements will increase the work pressure of employees, resulting in disappointment, anxiety, burnout, and other negative emotions [17]. When the work resources provided by the enterprise are greater than the work requirements, sufficient work resources can effectively reduce 
the psychological and physical costs paid by employees in the work process. It also enables employees to achieve their work objectives better, motivating individual learning, development, growth, and other related work factors. In this way, positive work emotions such as employee satisfaction and happiness can be improved [18].

Employees' emotions will be affected by individual factors, such as their emotional traits, whereas employees' social role determines that their emotions will also be affected by organizational factors, such as work events, leadership, and family activities. Su and Dan [19] showed that employees with positive emotional traits have a more positive evaluation of the work situation, are more optimistic and open-minded when dealing with work events, and will actively adopt more coping methods. In contrast, employees with negative emotional traits are more pessimistic about work and life, have low enthusiasm to deal with work tasks, and have poor performance [19]. Therefore, they experience more negative emotions and have more difficulty recovering from these emotions [20]. Therefore, when employees perceive that HPWS is a motivational effect, such employees show positive work emotions. In contrast, when employees perceive that HPWS is a performance effect, such employees show negative work emotions. Therefore, this study proposes the following hypotheses:

H3: investment and incentive practice perception have a significant positive impact on positive emotions

H4: investment and incentive practice perception have a significant positive impact on negative emotions

H5: performance enhancement practice perception has a significant positive impact on positive emotions

H6: performance enhancement practice perception has a significant positive impact on negative emotions

2.1.3. Employee Emotion and ECWB. Employees will have certain emotions during the description and perception of HRM practices, and these emotions have an important influence on subsequent behavioral responses [6]. Spector et al. [11] proposed the stressor-emotion model. This model posits that counterproductive work behavior is a stress response to the organizational environment stress. For example, the loss of work resources is too large and the work is too heavy, leading to employees' frustration and thus resulting in anxiety, anger, and a series of negative emotions. Finally, these emotions can trigger ECWB. Fredrickson [21] believed that positive emotions can broaden individuals' attention focus and behavioral skills, thus supplementing individuals' social, intellectual, and physical resources. Individuals with positive emotions are more likely to choose organization citizen behavior to maintain such a pleasant experience and reduce ECWB [22]. Negative emotions are often associated with high aggression [23]. For instance, Way [24] found that the negative emotions generated by employees in the work process would stimulate the occurrence of organization-oriented and interpersonal counterproductive behaviors. Meanwhile, Dalal et al. [25] further confirmed that employees' positive emotions promote their greater organizational citizenship behavior. In contrast, when employees have negative emotions, the unpleasant emotional experience will stimulate individuals to take counterproductive behaviors to vent their inner displeasure. Therefore, this study proposed the following hypotheses:

H7: positive emotions have a significant negative influence on ECWB

H8: negative emotions have a significant positive influence on ECWB

2.1.4. Mediating Effect of Employee Emotion. Emotion was seen as a driving force or one-dimensional impulse and as a causal antecedent variable or variable between the intervening stimulus environment and behavioral and cognitive responses [26]. Simply put, emotions are associated with specific events. Especially, the danger and opportunity are closely related to individual survival and development in the external environment. These require constant vigilance of the individual. Once an event occurs, the emotions it triggers are not just subjective feelings of the individual. At the same time, it indicates that the individual enters the state of coping with stress, that is, an emotion-induced behavioral tendency. Both positive and negative emotions can stimulate action tendency and behavior intention $[27,28]$.

Based on the work affective event theory, emotion is considered a mediating process mechanism in the event-outcome relationship [7]. Edwards and Wright [29] conjectured that the HPWS includes a series of human resource practices and changes in employees' behavior through some intermediary variables (e.g., work attitude). The emotion's social function can help individuals adapt to the environment. It is also advantageous to the individual interpersonal interaction, positive emotional experience, and expression that can improve social relations [30]. George and Zhou [31] confirmed that positive and negative emotions have a significant influence on employee behavior; when employees are in a positive mood, they are more prone to helping behavior and consciousness of cooperation, reducing conflict, positively interacting with other employees, and forming a relationship of mutual trust. Meanwhile, negative emotions can lead to extreme behavior in the workplace, such as a jealousy, resulting in an angry employee who takes hostile actions and may try framing others in a dirty way. Therefore, this study presents the following hypotheses:

H9: positive emotion plays a mediating role between investment and incentive practice perception and ECWB

H10: negative emotions played a mediating role between investment and incentive practice perception and ECWB

H11: positive emotions play a mediating role between the performance enhancement practice perception and ECWB

H12: negative emotions play a mediating role between the performance enhancement practice perception and ECWB 
2.1.5. Moderating Effect of Organizational Commitment. Academic circles are widely concerned about the role of organizational commitment in the relationship between enterprises and employees. Becker [32] first proposed organizational commitment. It is deemed the gradual increase in an individual's investment in the organization over time. This creates an incentive to align with the organization. Organizational commitment includes employees' emotional attachment to the organization, work dependence, and professional ethics constraints [33]. Ahmad [34] also confirmed that organizational commitment affects employees' work motivation. Organizational commitment can reinforce positive employee behavior. For example, organizational commitment is positively correlated with organizational citizenship behavior, civic virtue, politeness, and altruism displayed by employees [35], simultaneously weakening employees' negative behaviors; higher organizational commitment may reduce ECWB [36]. Therefore, in the implementation process of HPWS, organizational commitment can effectively adjust the work attitude of employees; employees with high emotional commitment can effectively transform work pressure into work motivation and produce higher job performance [8]. Therefore, this study makes the following hypotheses:

H13: organizational commitment plays a moderating role between the positive emotions and ECWB

H14: organizational commitment plays a moderating role between the negative emotions and ECWB

2.2. Research Model. Based on the above assumptions, the conceptual framework model is studied in this study, as shown in Figure 1.

\section{Research Design}

3.1. Research Samples. In this study, the employees of enterprises from Guangzhou, Shenzhen, Nanning, Chengdu, and Jiangsu were selected as the research objects in China. The investigated enterprises all constructed relatively perfect HPWS and collected data by using the questionnaire survey. The questionnaires were distributed in three ways: (1) distributing questionnaires on the site of enterprise staff training courses; (2) through the help of friends and relatives in their company; and (3) through the Questionnaire Star. To make the collected data more authentic and effective, the survey was conducted anonymously when the questionnaire was distributed on the spot. Meanwhile, members of the research group would guide the respondents to ensure their understanding of the questionnaire items and their truthful answers. For the collected questionnaires, more than $2 / 3$ of the same options and the questionnaires with missing answers were removed to ensure the validity of the questionnaire data. A total of 500 questionnaires were sent out, and 336 were effectively received with an effective recovery rate of $67.2 \%$.

3.2. Scale Design. In this study, maturity scales were used to ensure the reliability and validity of the scales. The scale includes five parts: basic information, HPWS perception, employee emotion, organizational commitment, and ECWB. In addition to basic information, other parts were scored on a 5-point Likert scale.

3.2.1. HPWS Perception. Based on the scale of Batt and Colvin [4], this study divided employees' HPWS perception into the following: investment and incentive practice perception (IIPP) and performance enhancement practice perception (PEPP). Each dimension contains four questions, with a total of eight questions (W1-W4, P1-P4). For example, "I think HPWS can realize my personal achievements; I think HPWS gives me too much work pressure." The items are rated from $1=$ strongly disagree to $5=$ strongly agree; the higher the score, the higher the perception of HPWS.

3.2.2. Employee Mood. Based on the Panas scale of Watson et al. [37], this study divides employee emotions into two dimensions: positive emotions (PE) (e.g., confidence, happiness, and enthusiasm) and negative emotions (NE) (e.g., anger, anxiety, and hostility). Each dimension contains three items for a total of six items (G1-G3, N1-N3) and rated from $1=$ strongly disagree to $5=$ strongly agree. The higher the score, the higher the employee's positive or negative emotions.

3.2.3. Organizational Commitment (OC). This study used Mayer and Allen's [38] Organizational Commitment Scale for reference and selected three representative items for measuring this study (O1-O3). For example, "I have a deep attachment to the company. I will not have a better chance of advancement if I leave the company." The items are rated from $1=$ strongly disagree to $5=$ strongly agree; the higher the score, the higher the employees' organizational commitment.

3.2.4. ECWB. ECWB scale is a measure of employees' negative behavior in the workplace, and the respondents may be unwilling to truthfully report their counterproductive behavior due to fear, leading to unrealistic measured results. Therefore, this study adopted the method of transfer reference point, and the respondents were asked to answer the counterproductive work behavior of their colleagues, so as to indirectly obtain the data of counterproductive work behavior of the respondents. To a certain extent, it avoids the interviewees' false answers for fear of privacy exposure, leading to the distortion of the collected data [39]. This study refers to the counterproductive behavior scale of $\mathrm{Ma}$ [40], which contains six items (C1-C3). For example, "My colleague intentionally procrastinates work; My colleague is abusive." The items are rated from $1=$ completely disagree to $5=$ completely agree; the higher the score, the more ECWB occurs.

\section{Data Analysis}

4.1. Descriptive Statistical Analysis. As shown in Table 1, the relationship model proposed in this study includes 6 


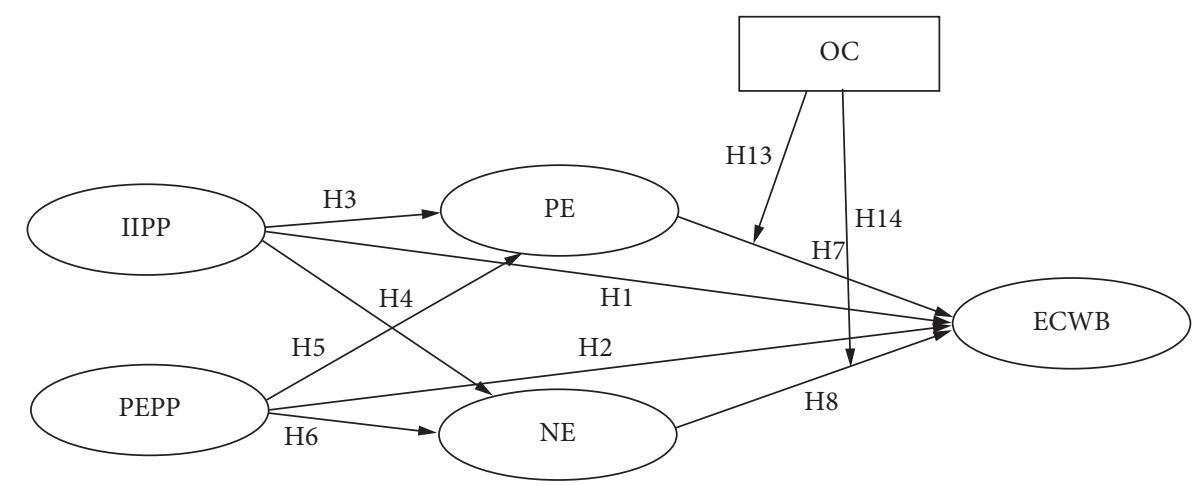

Figure 1: The conceptual framework model.

TABLe 1: Descriptive statistical analysis $(N=336)$.

\begin{tabular}{|c|c|c|c|c|c|}
\hline Latent variables & Item & Mean & Standard deviation & Skewness & Kurtosis \\
\hline \multirow{4}{*}{ IIPP } & $\mathrm{W} 1$ & 3.820 & 1.222 & -0.805 & -0.379 \\
\hline & W2 & 3.760 & 1.156 & -0.725 & -0.311 \\
\hline & W3 & 3.720 & 1.180 & -0.611 & -0.658 \\
\hline & W4 & 3.860 & 1.226 & -0.821 & -0.386 \\
\hline \multirow{4}{*}{ PEII } & P1 & 3.440 & 1.261 & -0.31 & -0.973 \\
\hline & $\mathrm{P} 2$ & 3.430 & 1.298 & -0.334 & -1.039 \\
\hline & P3 & 3.420 & 1.255 & -0.32 & -0.948 \\
\hline & $\mathrm{P} 4$ & 3.520 & 1.246 & -0.327 & -0.968 \\
\hline \multirow{3}{*}{$\mathrm{PE}$} & G1 & 3.590 & 1.062 & -0.243 & -0.822 \\
\hline & $\mathrm{G} 2$ & 3.590 & 1.024 & -0.293 & -0.585 \\
\hline & G3 & 3.660 & 1.025 & -0.431 & -0.413 \\
\hline \multirow{3}{*}{$\mathrm{NE}$} & N1 & 3.610 & 1.001 & -0.341 & -0.589 \\
\hline & $\mathrm{N} 2$ & 3.590 & 1.030 & -0.324 & -0.472 \\
\hline & N3 & 3.560 & 1.023 & -0.372 & -0.376 \\
\hline \multirow{3}{*}{$\mathrm{OC}$} & O1 & 3.750 & 1.081 & -0.467 & -0.885 \\
\hline & $\mathrm{O} 2$ & 3.810 & 1.001 & -0.616 & -0.276 \\
\hline & $\mathrm{O} 3$ & 3.690 & 1.101 & -0.409 & -0.806 \\
\hline \multirow{6}{*}{ ECWB } & $\mathrm{C} 1$ & 4.140 & 1.128 & -1.382 & 1.175 \\
\hline & C2 & 3.780 & 1.084 & -0.613 & -0.269 \\
\hline & $\mathrm{C} 3$ & 3.770 & 1.031 & -0.609 & -0.044 \\
\hline & $\mathrm{C} 4$ & 4.000 & 1.079 & -1.047 & 0.457 \\
\hline & C5 & 3.750 & 1.094 & -0.509 & -0.583 \\
\hline & C6 & 3.910 & 1.126 & -0.979 & 0.326 \\
\hline
\end{tabular}

variables and 23 items, including investment and incentive practice perception, performance enhancement practice perception, positive emotion, negative emotion, organizational commitment, and ECWB. A 5-point Likert scale was used for all scales, with a maximum value of 5 and a minimum value of 1 . For the scales, the higher the score, the higher the corresponding evaluation level. Descriptive statistical results of 23 measurement items are shown in Table 2. The minimum mean value is 3.420 , and the maximum value is 4.140 . Generally speaking, the respondents are objective with the evaluation of each variable. The minimum standard deviation is 1.001 , and the maximum is 1.298 , both of which differ greatly from the total score of 5, indicating a low degree of data dispersion. The absolute value of skewness of all measurement questions is less than 2 , and the absolute value of kurtosis is less than 2 . The samples obey a normal distribution, which can be used for further analysis.

\subsection{Reliability and Validity Analysis}

4.2.1. Reliability Analysis. As shown in Table 3, the Cronbach's alpha coefficients of each variable are all greater than 0.8. If they were to get down as Cronbach's coefficients and the Corrected Item Total Correlation (CITC) is between 0.7 and 0.9 , greater than 0.5 , it indicates that all 23 items have passed the test and cannot be removed. Cronbach's alpha coefficient is greater than 0.8 , indicating that the questionnaire has a high level of reliability, and the scale has high internal consistency and stability. 
TABLE 2: Analysis of convergence validity.

\begin{tabular}{|c|c|c|c|c|c|c|c|}
\hline Latent variables & Item & Estimate (std.) & S.E & C.R & $P$ & $\mathrm{CR}$ & Ave \\
\hline \multirow{4}{*}{ IIPP } & $\mathrm{W} 1$ & 0.860 & & & & \multirow{4}{*}{0.893} & \multirow{4}{*}{0.676} \\
\hline & $\mathrm{W} 2$ & 0.789 & 0.051 & 16.989 & $* * *$ & & \\
\hline & W3 & 0.773 & 0.053 & 16.501 & $* * *$ & & \\
\hline & W4 & 0.862 & 0.052 & 19.268 & $* * *$ & & \\
\hline \multirow{4}{*}{ PEII } & $\mathrm{P} 1$ & 0.866 & & & $* * *$ & \multirow{4}{*}{0.91} & \multirow{4}{*}{0.717} \\
\hline & $\mathrm{P} 2$ & 0.846 & 0.051 & 19.66 & $* * *$ & & \\
\hline & P3 & 0.817 & 0.051 & 18.597 & $* * *$ & & \\
\hline & $\mathrm{P} 4$ & 0.857 & 0.049 & 20.083 & $* * *$ & & \\
\hline \multirow{3}{*}{$\mathrm{PE}$} & G1 & 0.873 & & & $* * *$ & \multirow{3}{*}{0.885} & \multirow{3}{*}{0.720} \\
\hline & $\mathrm{G} 2$ & 0.862 & 0.051 & 18.566 & $* * *$ & & \\
\hline & G3 & 0.809 & 0.051 & 17.385 & $* * *$ & & \\
\hline \multirow{3}{*}{$\mathrm{NE}$} & N1 & 0.865 & & & $* * *$ & \multirow{3}{*}{0.88} & \multirow{3}{*}{0.710} \\
\hline & $\mathrm{N} 2$ & 0.851 & 0.056 & 18.121 & $* * *$ & & \\
\hline & N3 & 0.811 & 0.056 & 17.193 & $* * *$ & & \\
\hline \multirow{3}{*}{ OC } & O1 & 0.859 & & & $* * *$ & \multirow{3}{*}{0.896} & \multirow{3}{*}{0.714} \\
\hline & $\mathrm{O} 2$ & 0.869 & 0.048 & 19.337 & $* * *$ & & \\
\hline & $\mathrm{O} 3$ & 0.855 & 0.053 & 18.976 & $* * *$ & & \\
\hline \multirow{6}{*}{ ECWB } & $\mathrm{C} 1$ & 0.826 & & & $* * *$ & \multirow{6}{*}{0.925} & \multirow{6}{*}{0.673} \\
\hline & $\mathrm{C} 2$ & 0.776 & 0.054 & 16.582 & $* * *$ & & \\
\hline & $\mathrm{C} 3$ & 0.725 & 0.053 & 15.071 & $* * *$ & & \\
\hline & $\mathrm{C} 4$ & 0.898 & 0.05 & 20.776 & $* * *$ & & \\
\hline & C5 & 0.769 & 0.055 & 16.374 & $* * *$ & & \\
\hline & C6 & 0.911 & 0.052 & 21.281 & $* * *$ & & \\
\hline
\end{tabular}

${ }^{*} P<0.05 ;{ }^{* *} P<0.01 ;{ }^{* * *} P<0.001$.

TABLE 3: Reliability of each variable.

\begin{tabular}{|c|c|c|c|c|}
\hline Latent variables & Item & CITC & Cronbach's alpha if item deleted & Cronbach's alpha \\
\hline \multirow{4}{*}{ IIPP } & W1 & 0.791 & 0.851 & \multirow{4}{*}{0.892} \\
\hline & W2 & 0.743 & 0.869 & \\
\hline & W3 & 0.726 & 0.875 & \\
\hline & W4 & 0.792 & 0.85 & \\
\hline \multirow{4}{*}{ PEII } & $\mathrm{P} 1$ & 0.808 & 0.879 & \multirow{4}{*}{0.910} \\
\hline & $\mathrm{P} 2$ & 0.797 & 0.883 & \\
\hline & P3 & 0.777 & 0.89 & \\
\hline & $\mathrm{P} 4$ & 0.801 & 0.882 & \\
\hline \multirow{3}{*}{$\mathrm{PE}$} & G1 & 0.797 & 0.816 & \multirow{3}{*}{0.884} \\
\hline & G2 & 0.780 & 0.832 & \\
\hline & G3 & 0.749 & 0.859 & \\
\hline \multirow{3}{*}{$\mathrm{NE}$} & N1 & 0.778 & 0.82 & \multirow{3}{*}{0.880} \\
\hline & $\mathrm{N} 2$ & 0.777 & 0.82 & \\
\hline & N3 & 0.746 & 0.849 & \\
\hline \multirow{3}{*}{ OC } & $\mathrm{O} 1$ & 0.792 & 0.851 & \multirow{3}{*}{0.895} \\
\hline & $\mathrm{O} 2$ & 0.797 & 0.849 & \\
\hline & $\mathrm{O} 3$ & 0.794 & 0.85 & \\
\hline \multirow{6}{*}{ ECWB } & $\mathrm{C} 1$ & 0.786 & 0.908 & \multirow{6}{*}{0.923} \\
\hline & $\mathrm{C} 2$ & 0.748 & 0.913 & \\
\hline & $\mathrm{C} 3$ & 0.691 & 0.921 & \\
\hline & $\mathrm{C} 4$ & 0.846 & 0.9 & \\
\hline & C5 & 0.736 & 0.915 & \\
\hline & C6 & 0.870 & 0.897 & \\
\hline
\end{tabular}

4.2.2. Validity Analysis. This study adopted the maturity scale to ensure high structural validity of the scale. Thus, the scale's convergence and discriminant validity were tested by SPSS.21 software.
Each item factor load value between 0.725 and 0.911 shows that the convergent validity is higher, the combination reliability $(\mathrm{CR})$ values of the various dimensions are greater than 0.7, and AVE values were greater than 0.5 , 
$P<0.001$, suggesting a significant relationship between latent and measurement variables. This indicates that items are a good measure of the variable dimension, and therefore, the convergent validity of the scale is excellent.

As shown in Table 4, the square root of AVE is greater than the correlation coefficient among all dimensions, indicating significant differences among all scale items without common factors. Therefore, the scale has good discriminative validity.

\subsection{Empirical Analysis}

4.3.1. Model Fit Degree. The fitting indexes of the model are shown in the Table 5. The fitting indexes are: $\chi^{2} / d f=1.109$, $\mathrm{GFI}=0.951, \quad$ AGFI $=0.937, \quad \mathrm{NFI}=0.962, \quad$ TLI $=0.995$, $\mathrm{CFI}=0.996$, and RMSEA $=0.018$. The fitting indexes of the model meet the fitting standards of the comparison table, so the model path is analyzed.

4.3.2. Path Analysis. In this study, AMOS21.0 software was used for path analysis of the structural equation model (Figure 2), the path coefficient values of the structural equation model, and CR value (critical ratio). The path coefficient reflects the influence relationship and degree between variables. If the CR is greater than or equal to 1.96, a significant relationship exists between the variables at the 0.05 significance level [41].

Table 6 shows that by observing the path coefficients, CR and $\mathrm{P}$, of the eight hypotheses, six are supported and two are not supported. Among them, investment and incentive practice perception significantly affect positive emotions $(\beta=0.316, P<0.001)$, so $\mathrm{H} 1$ is supported. Perceiving performance enhancement practice has no significant positive effect on positive emotions $(\beta=0.024, P>0.05)$, so $\mathrm{H} 2$ is not supported; investment and incentive practice perception had no significant positive effect on negative emotions $(\beta=0.012$, $P>0.05$ ), so H3 was not supported. Performance enhancement practice perceived has a significant positive effect on negative emotions $(\beta=0.385, P<0.001)$, so H4 is supported. The investment and incentive practice perception has a significant negative impact on the ECWB $(\beta=-0228$, $P<0.001$ ), so H5 is supported. Performance enhancement practice perceived has a significant positive effect on ECWB ( $\beta=0.502, P<0.001)$, so H6 is supported. Positive emotions significantly negatively impact ECWB $(\beta=-0.167$, $P<0.001)$, so $\mathrm{H7}$ is supported. Negative emotions had a significant positive effect ECWB $(\beta=0.319, P<0.001)$, and $\mathrm{H} 8$ hypothesis was supported.

Particularly, the negative effect of the performance enhancement practice perception on ECWB is significantly higher than the positive effect of the investment and incentive practice perception on the ECWB, indicating that the promotion effect of the HPWS on the ECWB is stronger than the inhibition effect.

4.3.3. Mediating Effect Test. In this study, AMOS21.0 was used to run the Bootstrap method. The selection was repeated 5000 times, the confidence interval standard was $95 \%$, and the deviation correction method was used for testing. Since the model in this study is a multiple mediation model, only the total mediation effect results can be obtained through a single analysis, rather than the specific mediation effect. Therefore, the syntax of AMOS software is adopted to assign all relevant paths to calculate the specific nonstandardized and standardized mediation effects, respectively.

Table 7 shows four mediation hypotheses, of which two are supported, whereas two are not. In the IIPP-PE-ECWB path, $\beta=-0.053, P<0.001,95 \%$ confidence interval is $[-0.093,-0.020]$, excluding 0 , indicating that positive emotions have a significant mediating effect between investment and incentive practice perception and ECWB, so $\mathrm{H} 9$ is supported. In the PEPP-PE-ECWB path, $\beta=-0.004$, $P>0.05,95 \%$ confidence interval is $[-0.027,0.018]$, including 0 , indicating that positive emotion has no significant mediating effect between performance enhancement practice perception and ECWB, so H10 is not supported. In the IIPP-NE-ECWB path, $\beta=0.004, P>0.05$, the mediating effect is 0.004 , and the corresponding $95 \%$ confidence interval is $[-0.039,0.043]$, including 0 , indicating that the mediating effect of negative emotions on the relationship between investment and incentive practice perception and ECWB is not significant, so H11 is not supported. In the path of PEPP-NE-ECWB, $\beta=0.123, P<0.001,95 \%$ confidence interval is $[0.070,0.185]$, excluding 0 , indicating that negative emotions have a significant mediating effect between performance enhancement practice perception and ECWB, so H12 is supported.

4.3.4. Hypothesis Test of Moderating Effect. In this study, three multivariate regression models were established by using multivariate regression. The first model introduces control variables; the second model introduces control variables, independent variables, and moderating variables; and the third model introduces control variables, independent variables, moderating variables, and the interaction term between independent variables and moderating variables.

According to the data in Table 8, regression coefficients of the control variables in Model 1 are not significant, indicating that gender, age, working years, educational background, and position have no significant influence on the ECWB. In Model 2, the independent variables positive emotion $(\beta=-0.224, t=-4.425)$ and organizational commitment $(\beta=0.418, t=8.256)$ had significant effects on ECWB. In Model 3, the regression coefficient of the interaction term of positive emotion and organizational commitment is $(\beta=0.042, t=0.835)$, indicating that the interaction term has no significant effect on ECWB, and the $R^{2}$ of model 2 is 0.196 , the $R^{2}$ of model 3 is 0.198 , not significantly improved, indicating that the model's explanatory ability is not strong. Therefore, the moderating variable organizational commitment has no significant moderating effect on the relationship between positive emotions and ECWB, thereby rejecting $\mathrm{H} 13$. 
TABLE 4: Discriminant validity analysis.

\begin{tabular}{|c|c|c|c|c|c|c|}
\hline & IIPP & PEPP & $\mathrm{PE}$ & $\mathrm{NE}$ & $\mathrm{OC}$ & ECWB \\
\hline IIPP & 0.822 & & & & & \\
\hline PEPP & 0.186 & 0.846 & & & & \\
\hline $\mathrm{PE}$ & 0.322 & 0.081 & 0.848 & & & \\
\hline $\mathrm{NE}$ & 0.081 & 0.386 & 0.097 & 0.842 & & \\
\hline $\mathrm{OC}$ & 0.16 & 0.336 & 0.199 & 0.455 & 0.844 & \\
\hline ECWB & 0.163 & 0.571 & 0.171 & 0.479 & 0.401 & 0.820 \\
\hline
\end{tabular}

TABLE 5: Fitting index of structural equation model.

\begin{tabular}{|c|c|c|c|c|c|c|c|}
\hline Indicators & $\chi^{2} / d f$ & GFI & AGFI & NFI & TLI & CFI & RMSEA \\
\hline Statistics & 1.109 & 0.951 & 0.937 & 0.962 & 0.995 & 0.996 & 0.018 \\
\hline Reference & $<3$ & $>0.8$ & $>0.8$ & $>0.9$ & $>0.9$ & $>0.9$ & $<0.08$ \\
\hline Up to standard & Yes & Yes & Yes & Yes & Yes & Yes & Yes \\
\hline
\end{tabular}

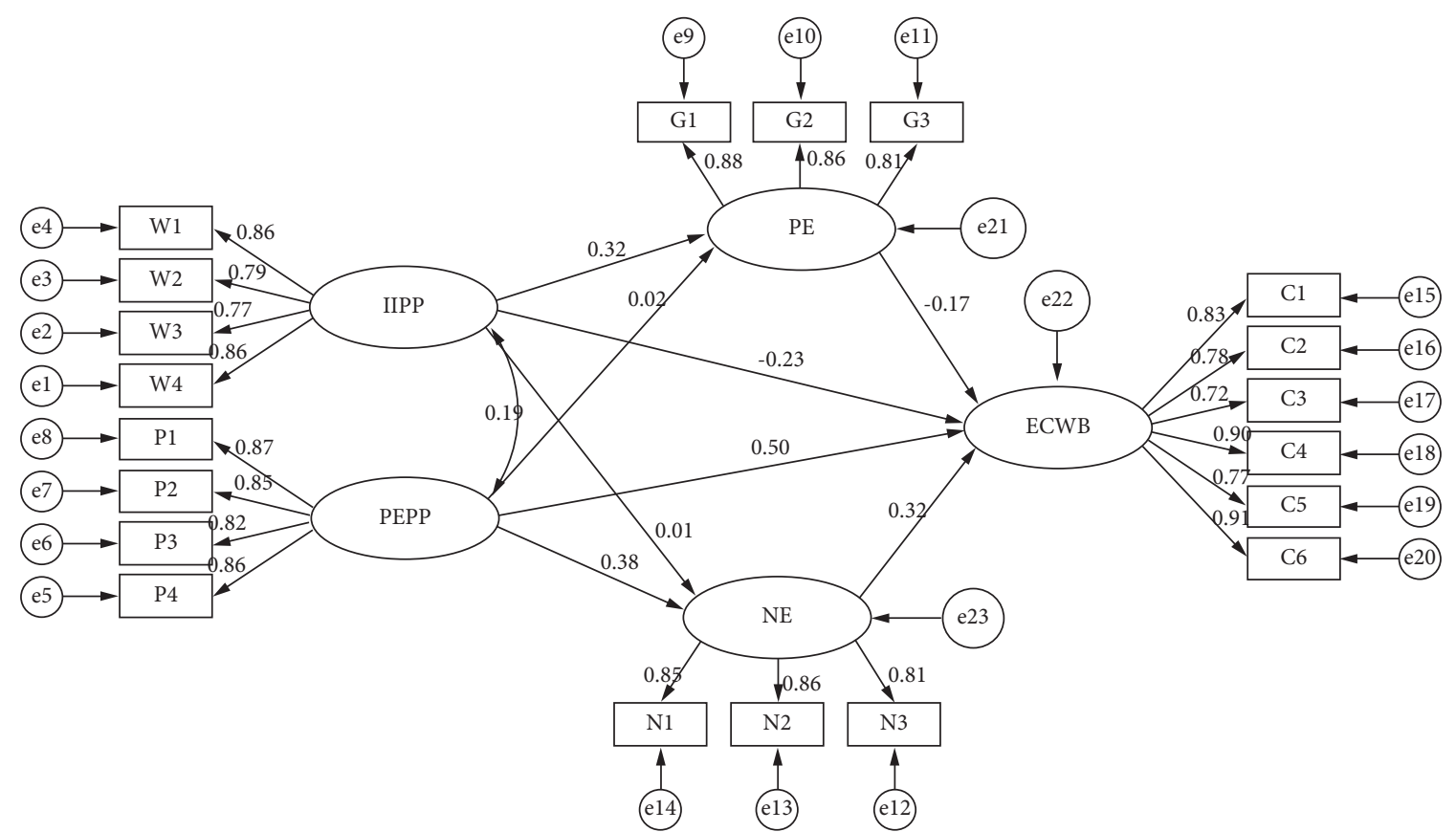

FIgURE 2: Structure path diagram.

TABLE 6: Path coefficients of structural equation model.

\begin{tabular}{lccccccc}
\hline & Assuming that path & & Estimate (std.) & S.E. & C.R. & $P$ & Hypothesis \\
\hline PE & $<---$ & IIPP & 0.316 & 0.054 & 5.167 & ${ }^{* * *}$ & Supported \\
PE & $<---$ & PEPP & 0.024 & 0.052 & 0.411 & 0.681 & Not supported \\
NE & $<---$ & IIPP & 0.012 & 0.046 & 0.199 & 0.843 & Not supported \\
NE & $<---$ & PEPP & 0.385 & 0.048 & 6.265 & $* * *$ & Supported \\
ECWB & $<---$ & IIPP & -0.228 & 0.044 & -4.570 & $* * *$ & Supported \\
ECWB & $<---$ & PEPP & 0.502 & 0.049 & 9.053 & $* * *$ & Supported \\
ECWB & $<---$ & PE & -0.167 & 0.049 & -3.427 & $* * *$ & Supported \\
ECWB & $<---$ & NE & 0.319 & 0.059 & 6.054 & Supported \\
\hline
\end{tabular}

${ }^{*} P<0.05 ;{ }^{* *} P<0.01 ;{ }^{* * *} P<0.001$. 
TABLE 7: Mediating effect test.

\begin{tabular}{lccccc}
\hline Assuming that path & Estimate & Lower & Upper & $P$ & Assuming that \\
\hline IIPP-PE-ECWB & -0.053 & -0.093 & -0.020 & 0.001 & Supported \\
PEPP-PE-ECWB & -0.004 & -0.027 & 0.018 & 0.742 & Not supported \\
IIPP-NE-ECWB & 0.004 & -0.039 & 0.043 & 0.861 Not supported \\
PEPP-NE-ECWB & 0.123 & 0.070 & 0.185 & 0.001 & Supported \\
\hline
\end{tabular}

TABLE 8: Examine the moderating effect of organizational commitment on positive emotion and counterproductive behavior of employees.

\begin{tabular}{|c|c|c|c|}
\hline \multirow{2}{*}{ Variable } & \multicolumn{3}{|c|}{ ECWB } \\
\hline & Model 1 & Model 2 & Model 3 \\
\hline \multicolumn{4}{|c|}{ Control variables } \\
\hline Gender & $-0.016(-0.292)$ & $-0.052(-1.047)$ & $-0.053(-1.060)$ \\
\hline Age & $-0.015(-0.263)$ & $0.013(0.255)$ & $0.014(0.281)$ \\
\hline Working years & $-0.048(-0.866)$ & $-0.029(-0.585)$ & $-0.027(-0.549)$ \\
\hline Education background & $-0.025(-0.450)$ & $-0.007(0.133)$ & $-0.009(-0.176)$ \\
\hline Position & $-0.067(-1.205)$ & $-0.083(-1.671)$ & $-0.082(-1.638)$ \\
\hline \multicolumn{4}{|c|}{ The independent variables } \\
\hline $\mathrm{PE}$ & & $-0.224^{* * *}(-4.425)$ & $-0.224^{* * *}(-4.426)$ \\
\hline $\mathrm{OC}$ & & $0.418^{* * *}(8.256)$ & $0.417^{* * *}(8.223)$ \\
\hline \multicolumn{4}{|c|}{ Interactive items } \\
\hline $\mathrm{PE}^{*} \mathrm{OC}$ & & & $0.042(0.835)$ \\
\hline$R^{2}$ & 0.008 & 0.196 & 0.198 \\
\hline$\triangle R^{2}$ & -0.007 & 0.179 & 0.178 \\
\hline$F$ & 0.518 & $11.41^{* * *}$ & $10.062^{* * *}$ \\
\hline
\end{tabular}

${ }^{*} P<0.05 ;{ }^{* *} P<0.01 ;{ }^{* * *} P<0.001$.

As shown in Table 9, the regression coefficients of the control variables in Model 1 were not significant, thereby indicating that gender, age, working years, educational background, and position had no significant effect on the ECWB. In Model 2, the independent variables of negative emotion $(\beta=0.339, \quad t=6.396)$ and organizational commitment $(\beta=0.283, t=4.949)$ had significant effects on CWB. In Model 3 , the regression coefficient of the interaction term of negative emotion and organizational commitment is $(\beta=-0.145$, $t=-2.862)$, thereby indicating that the interaction term has a significant impact on the ECWB, and the $R^{2}$ of Model 2 is 0.242 , and the $R^{2}$ of Model 3 is 0.261 , which is significantly increased, thereby indicating that the explanatory ability of the model is enhanced. Therefore, the moderating variable organizational commitment has a significant moderating effect on the impact of negative emotions on ECWB, so H14 is supported.

According to the moderating effect chart (Figure 3), in the case of high organizational commitment, negative emotions have a weak positive effect on counterproductive behavior, while in the case of low organizational commitment, negative emotions have a strong positive effect on counterproductive behavior. According to the empirical results of this paper, organizational commitment only has a negative moderating effect on the relationship between negative emotions and ECWB.

\section{Discussion}

This study aims to establish a practice model by exploring the influence path and internal influence mechanism of HPWS perception on ECWB. It provides a scientific and effective HRM method for modern enterprises to reduce ECWB.

The results of this study confirm the two sides of HPWS. HPWS brings high work resources (participation in decision-making, etc.) and high work requirements (performance appraisal, etc.), that is, HPWS has both promoting and inhibiting effects on ECWB. This conclusion complements Wang et al.'s [3] research on the one-sided nature of HPWS.

At the same time, this study combined with resource conservation theory to explore the mediating role of employee emotion. The research results confirmed the viewpoint of Edwards and Wright [29] that HPWS affects employee behavior through some intermediary variable. In addition, the research further verifies the resource conservation theory [7]. When the organization can effectively replenish the resources consumed by employees in the process of work in time, the work resources can effectively reduce the physical and psychological costs paid by the work requirements. Work factors enable employees to achieve work goals and promote learning, development, and growth [42] , and help employees to have a positive work attitude, promote the production of positive emotions, and reduce ECWB [43, 44]. By contrast, when the enterprise's work requirements of employees are higher than the work resources it provides, employees' input in work does not get a good return. It will increase the work pressure of employees, resulting in disappointment, anxiety, burnout, and other negative emotions. In this case, the employee is in a state of resource deprivation. In order to restore the balance of resources, employees will reduce their commitment to work. 
TABLE 9: The moderating effect of organizational commitment on negative emotions and counterproductive behavior of employees.

\begin{tabular}{|c|c|c|c|}
\hline \multirow{2}{*}{ Variable } & \multicolumn{3}{|c|}{ Staff counterproductive behavior } \\
\hline & Model 1 & Model 2 & Model 3 \\
\hline \multicolumn{4}{|c|}{ Control variables } \\
\hline Gender & $-0.016(-0.292)$ & $-0.036(-0.748)$ & $-0.027(-0.554)$ \\
\hline Age & $-0.015(-0.263)$ & $-0.037(-0.751)$ & $-0.04(-0.821)$ \\
\hline Working years & $-0.048(-0.866)$ & $-0.036(-0.749)$ & $-0.02(-0.413)$ \\
\hline Education background & $-0.025(-0.450)$ & $-0.012(-0.256)$ & $0.006(0.130)$ \\
\hline Position & $-0.067(-1.205)$ & $-0.052(-1.064)$ & $-0.051(-1.067)$ \\
\hline \multicolumn{4}{|c|}{ The independent variables } \\
\hline $\mathrm{NE}$ & & $0.339^{* * *}(6.396)$ & $0.336^{* * *}(6.397)$ \\
\hline $\mathrm{OC}$ & & $0.238^{* * *}(4.494)$ & $0.199^{* * *}(3.670)$ \\
\hline \multicolumn{4}{|c|}{ Interactive items } \\
\hline $\mathrm{NE} \times \mathrm{OC}$ & & & $-0.145^{* *}(-2.862)$ \\
\hline$R^{2}$ & 0.008 & 0.242 & 0.261 \\
\hline$\triangle R^{2}$ & -0.007 & 0.226 & 0.243 \\
\hline$F$ & 0.518 & $14.986^{* * *}$ & $14.424^{* * *}$ \\
\hline
\end{tabular}

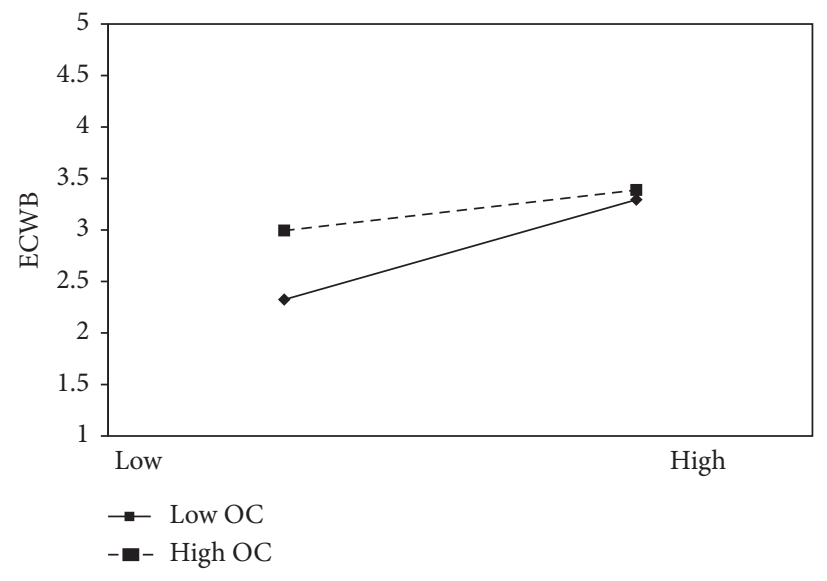

Figure 3: Moderating effect diagram.

In addition, the moderating role of organizational commitment was further explored. Meanwhile, Hunter and Thatcher's [8] conclusion is verified, and organizational commitment can promote employees' positive behavior and organizational citizenship behavior. According to the results of this study, organizational commitment can effectively regulate negative ECWB. For example, employees will try to change themselves, or speak to the organization and wait for the organization to change [43].

The results also showed that the influence coefficient $\beta$-value $(\beta=0.502)$ of performance enhancing practice perception on ECWB was significantly higher than that of investment and incentive practice perception on ECWB $(\beta=0.319)$. This result indicates that an HPWS has a stronger promotion effect on ECWB with negative emotions than employees with positive emotions [45].
Therefore, employees with negative emotions are more likely to engage in ECWB.

Therefore, this study proposes the following HPWS fivelevel model from five levels: strategy level, implementation level, employee perception level, effect level, and decision level (Figure 4). HPWS five-level model makes up for the one-sided nature that HPWS only emphasizes high performance. This model combines the dual characteristics of HPWS and focuses on every stage from the implementation of the HPWS strategy to feedback on the results. In view of different types of employees, the corresponding HRM means are put forward. This model makes up for the limitation of existing HPWS which only focuses on high performance and ignores employee perception. It provides a scientific and effective solution to promote the benefits that both employers and employees can reach an agreement on. 


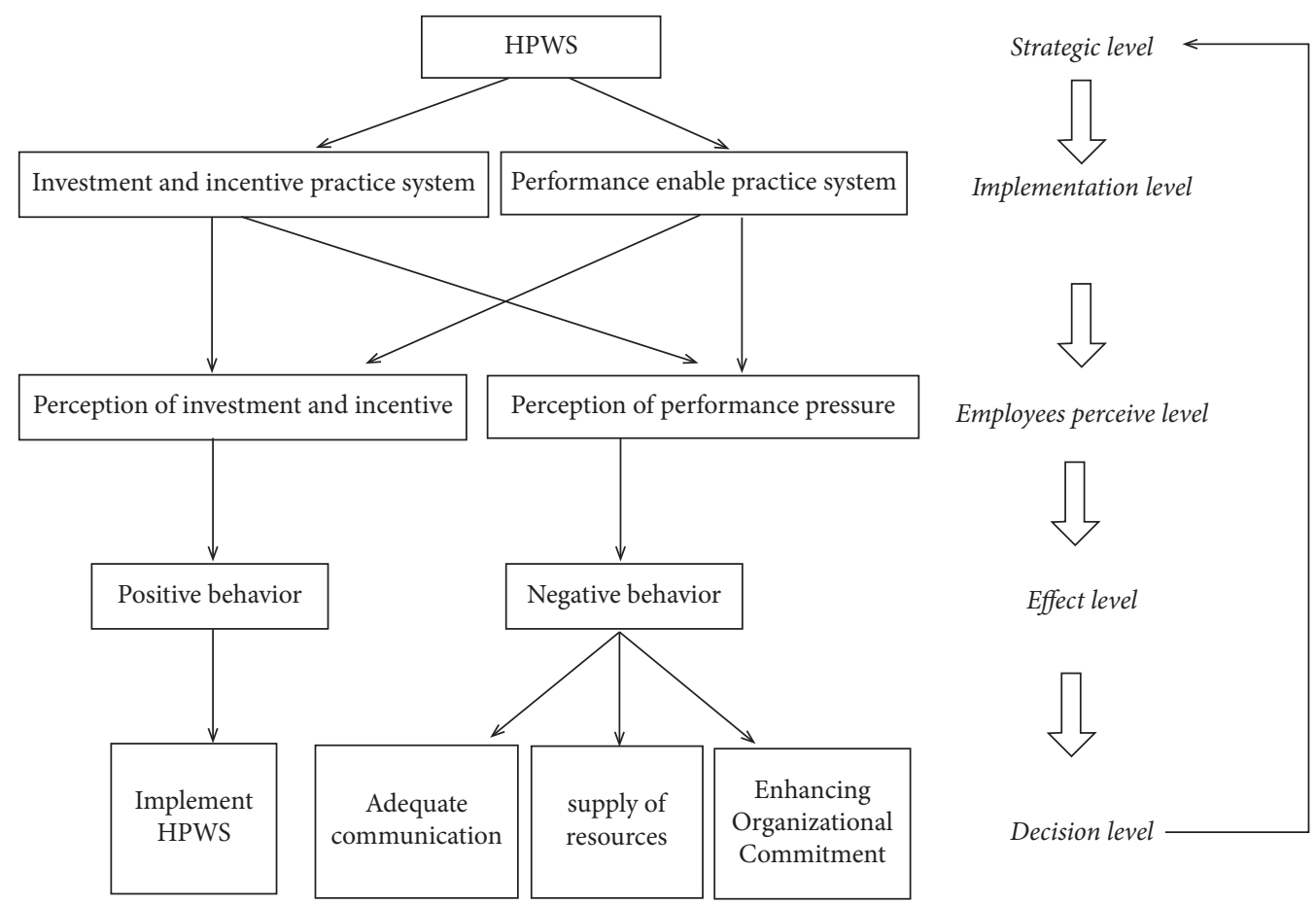

FIGURE 4: Five-level HPWS model.

\section{Conclusion}

This study contributes to the existing literature in the following ways: First, it verifies the duality of HPWS from the perspective of employee perception. Most of the previous studies focused on the impact of HPWS on improving employee performance, and few explained the dual effects of HPWS from the perspective of employee perception, that is, the negative and positive effects. This study provides a new way to explain the mechanism between HPWS and ECWB, and expands the theoretical basis of HPWS perception. Second, it explores the mediating effect of employee emotion. This study combines resource conservation theory and emotional event theory to incorporate positive and negative emotions of employees into the model. This paper explains the internal mechanism of HPWS's influence on ECWB with different individual emotional traits and enriches the HPWS' perception model. Thirdly, it complements the moderating effect of organizational commitment. No previous research has proposed the moderating effect of organizational commitment on ECWB. This study further supplements the research model of HPWS. Fourthly, the HPWS five-level model is constructed. In the process of implementing HPWS, the negative work emotions and behaviors of employees caused by excessive emphasis on high performance are solved. It provides a theoretical basis and practical guidance for HRM practice.

Implications of this study for management: First, when implementing HRM practices, enterprises should pay attention to the differences in employees' perception, strengthen communication with employees, and help employees understand the strategic purpose of the organization. Second, HPWS does not promote the high performance of every employee. Enterprises should build a more humane HPWS and pay more attention to the balance between family and work, rather than over-strengthening high performance, resulting in excessive pressure on employees, who may fail to achieve high-performance goals. Third, enterprises can consolidate employees' organizational commitment through corporate social responsibility and corporate culture, such as the emotion of the organization, professional involvement, professional ethics, etc., and they may take suggestions to the organization or wait for organizational changes to reduce the ECWB.

Due to the constraints of time and resources, this study still has some limitations, such as insufficient study sample size, single study method, and lack of group comparative analysis. In the future, this paper will continue to focus on the research on the impact of HPWS on employee behavior, and further expand the diversity of research contents and methods. For example, the influence of HPWS on other behaviors of employees is studied from the perspective of knowledge sharing. Qualitative and quantitative research methods were adopted to study the impact of HPWS implementation in different types of enterprises on employee behavior of different groups. In this way, more scientific and targeted management models and methods can be provided for different types of enterprises HR management practices.

\section{Data Availability}

The data used to support the findings of this study are included within the article.

\section{Conflicts of Interest}

The authors declare that they have no conflicts of interest. 


\section{Acknowledgments}

The authors are grateful for the support of the Youth Foundation of Ministry of Education of China (19YJC630141).

\section{References}

[1] S. Fox, P. E. Spector, and D. Miles, "Counterproductive work behavior (CWB) in response to job stressors and organizational justice:some mediator and moderator tests for autonomy and emotions," Journal of Vocational Behavior, vol. 59, no. 3, pp. 291-309, 2001.

[2] J. Y. Zhang and W. Y. Wang, "Investigation and analysis of negative behaviors in China's workplace," Finance and Trade Research, vol. 19, no. 6, pp. 101-107, 2008.

[3] J. Wang, J. Zhang, and W. N. Fan, "The relationship between high performance work system, psychological contract violation and counterproductive behavior: a moderated mediation model," Journal of Management in Engineering, vol. 32, no. 2, pp. 8-16, 2018.

[4] R. Batt and A. J. S. Colvin, “An employment systems approach to turnover: human resources practices, quite, dismissals and performance," Academy of Management Journal, vol. 54, no. 4, pp. 695-717, 2011.

[5] D. Van, K. Voorde, and S. Beuer, "The roie, attribution of employee employee attribution between high performance work systems and employee outcomes," Journal of Human Resource Management, vol. 25, no. 1, pp. 62-78, 2015.

[6] E. H. Hu, J. J. Hu, H. M. Shan, and M. L. Zhang, "Research on the influence of high performance work system attribution on counterproductive behavior based on the moderating effect of labor union practice," Journal of Management, vol. 165, no. 6, pp. 47-56, 2020.

[7] H. M. Weiss and R. Cropanzano, "Affective events theory: a theoretical discussion of the structure, causes and consequences of affective experiences at work," Research in Organizational Behavior, vol. 18, pp. 1-74, 1996.

[8] L. W. Hunter and S. M. B. Thatcher, "Feeling the heat: effects of stress, commitment, and job experience on job performance," Academy of Management Journal, vol. 50, no. 4, pp. 953-968, 2007.

[9] M. Huselid, S. E. Jackson, and R. S. Schuler, "Technical and strategic human resource management effectiveness as determinants of firm performance," Academy of Management Journal, vol. 40, no. 1, pp. 949-969, 1997.

[10] L. Zhou and K. Shen, "The influence of high performance work system perceived by employees on employee performance: an analysis based on chained mediation model," Science and Technology \& Economics, vol. 34, no. 199, pp. 76-80, 2021.

[11] P. E. Spector, S. Fox, L. M. Penney, K. Bruursema, A. Goh, and S. Kessler, "The dimensionality of counterproductivity: are all counterproductive behaviors created equal?" Journal of Vocational Behavior, vol. 68, no. 3, pp. 446-460, 2006.

[12] J. D. Shaw, B. R. Dineen, R. Fang, and R. F. Vellella, "Employee-organization exchange relationships,HRM practices and quit rates of good and poor performers," Academy of Management Journal, vol. 52, no. 5, pp. 1016-1033, 2009.

[13] Y. Su, X. Jiang, and Z. Lin, "Simulation and relationship strength: characteristics of knowledge flows among subjects in a regional innovation system," Science Technology and Society, pp. 1-23, 2021.
[14] P. Warr, "The measurement of well-being and other aspects of mental health," Journal of Occupational Psychology, vol. 63, no. 3, pp. 193-210, 1990.

[15] J. Godard, "A critical assessment of the high performance paradigm," British Journal of Industrial Relations, vol. 42, no. 2, pp. 349-378, 2004.

[16] J. Sun and H. Wang, "The potential mechanisms involved in the negative effect of high performance work system," Advances in Psychological Science, vol. 24, no. 7, pp. 1091-1106, 2016.

[17] A. Shantz, L. Arevshatian, K. Alfes, and C. Bailey, "The effect of HRM attributions on emotional exhaustion and the mediating roles of job involvement and work overload," Human Resource Management Journal, vol. 26, no. 2, pp. 172-191, 2016.

[18] H. Yang and J. Liao, "A new perspective of knowledge worker management:Job requirements-resource model," Science of Science and Management of Science and Technology, vol. 30, no. 10, pp. 171-176, 2009.

[19] Y. Su and L. Dan, "Interaction effects of government subsidies, $\mathrm{R} \& \mathrm{D}$ input and innovation performance of chinese energy industry: a panel vector autoregressive (PVAR) analysis," Technology Analysis \& Strategic Management, 2021.

[20] I. Papousek, K. Nauschnegg, M. Paechter, H. K. Lackner, N. Goswami, and G. Schulter, "Trait and state positive affect and cardiovascular recovery from experimental academic stress," Biological Psychology, vol. 83, no. 2, pp. 108-115, 2010.

[21] B. L. Fredrickson, "What good are positive emotions?" Review of General Psychology, vol. 2, no. 3, pp. 300-319, 1998.

[22] S. Jiafu, Y. Yu, and Y. Tao, "Measuring knowledge diffusion efficiency in R\&D networks," Knowledge Management Research and Practice, vol. 16, no. 2, pp. 208-219, 2018.

[23] K. M. Connor and J. R. T. Davidson, "Development of a new resilience scale: the connor-davidson resilience scale (CDRISC)," Depression and Anxiety, vol. 18, no. 2, pp. 76-82, 2010.

[24] S. A. Way, "High performance work systems and intermediate indicators of firm performance within the US small business sector," Journal of Management, vol. 28, no. 6, pp. 765-785, 2002.

[25] R. S. Dalal, H. Lam, and H. M. Weiss, "A within-person approach to work behavior and performance: concurrent and lagged citizenship-counterproductivity associations, and dynamic relationships with affect and overall job performance," Academy of Management Journal, vol. 52, no. 5, pp. 10511066, 2009.

[26] D. B. Lindsley, "Emotion," in Handbook of Experimental Psychology, S. S. Stevens, Ed., pp. 473-516, Wiley, New York, NY, USA, 1951.

[27] S. E. Hobfoll, "Conservation of resources. A new attempt at conceptualizing stress," American Psychologist, vol. 44, no. 3, p. $513,1989$.

[28] C. M. Barnes, L. Lucianetti, D. P. Bhave, and M. S. Christian, "You wouldn't like me when I'm sleepy\|: leaders' sleep, daily abusive supervision, and work unit engagement," Academy of Management Journal, vol. 58, no. 5, pp. 1419-1437, 2015.

[29] P. Edwards and M. Wright, "High-involvement work systems and performance outcomes: the strength of variable, contingent and context-bound relationships," International Journal of Human Resource Management, vol. 12, no. 4, pp. 568-585, 2001.

[30] X. Zhang and J. Su, "A combined fuzzy DEMATEL and TOPSIS approach for estimating participants in knowledge- 
intensive crowdsourcing," Computers \& Industrial Engineering, vol. 137, Article ID 106085, 2019.

[31] J. M. George and J. Zhou, "Dual tuning in a supportive context:joint contributions of positive mood, negativemood, and supervisory behaviors to employee creativity," Academy of Management Journal, vol. 50, no. 3, pp. 605-622, 2007.

[32] H. S. Becker, "Notes on the concept of commitment," The American Journal of Sociology, vol. 66, no. 1, pp. 32-40, 1960.

[33] J. P. Meyer, N. J. Allen, and I. R. Gellatly, "Affective and continuance commitment to the organization: evaluation of measures and analysis of concurrent and time-lagged relations," Journal of Applied Psychology, vol. 75, no. 6, p. 710, 1990.

[34] A. Ahmad, "The relationship among job characteristics organizational commitment and employee turnover intentions," Journal of Work-Applied Management, vol. 10, no. 1, pp. 74-92, 2018.

[35] M. Zayas-Ortiz, E. Rosario, E. Marquez, and P. C. Gruneiro, "Relationship between organizational commitments and organizational citizenship behaviour in a sample of private banking employees," International Journal of Sociology \& Social Policy, vol. 35, no. 1, pp. 91-106, 2015.

[36] B. Potdar, T. Garry, J. Guthrie, and J. Gnoth, "Yours truly:the role of organizational commitment in shoplifting prevention," International Journal of Retail \& Distribution Management, vol. 48, no. 1, pp. 70-91, 2020.

[37] D. Watson, L. A. Clark, and A. Tellegen, "Development and validationof brief measures of positive and negative affect:the PANAS scales," Journal of Personality and Social Psychology, vol. 54, no. 6, pp. 1063-1070, 1988.

[38] J. P. Meyer and N. J. Allen, "Links between work experiences and organizational commitment during the first year of employment: a longitudinal analysis," Journal of Occupational Psychology, vol. 61, no. 3, pp. 195-209, 1988.

[39] S. M. Stewart, M. N. Bing, H. K. Davison, D. J. Woehr, and M. D. McIntyre, "In the eyes of the beholder: a non-self-report measure of workplace deviance," Journal of Applied Psychology, vol. 94, no. 1, pp. 207-215, 2009.

[40] B. Ma, S. Liu, H. Lassleben, and G. Ma, "The relationships between job insecurity, psychological contract, breach and counterproductive workplace behavior," Personnel Review, vol. 48, no. 2, pp. 595-610, 2019.

[41] Z. L. Wen, J. T. Hou, and L. Zhang, "Comparison and application of moderating effect and mediating effect," Journal of Psychology, vol. 37, no. 2, pp. 268-274, 2005.

[42] T. A. Judge and R. Ilies, "Affect and job satisfaction: a study of their relationship at work and at home," Journal of Applied Psychology, vol. 89, no. 4, pp. 661-673, 2004.

[43] P. E. Spector and S. Fox, "An emotion-centered model of voluntary work behavior: some parallels between counterproductive work behavior and organizational citizenship behavior," Human Resource Management Review, vol. 12, no. 2, pp. 269-292, 2002.

[44] S. Jiafu, X. Chen, F. Zhang, N. Zhang, and F. Li, “An intelligent method for lead user identification in customer collaborative product innovation," Journal of Theoretical and Applied Electronic Commerce Research, vol. 16, no. 5, pp. 1571-1583, 2021.

[45] B. Parkinson, P. Totterdell, R. B. Briner, and S. Reynolds, Changing Moods: The Psychology of Mood and Mood Regulation, p. 254, Longman, London, UK, 1996. 